\title{
Article
}

\section{Exploring leadership in the context of dentistry in the UK}

Willcocks, Stephen George

Available at http://clok.uclan.ac.uk/14146/

Willcocks, Stephen George ORCID: 0000-0002-1764-5951 (2016) Exploring leadership in the context of dentistry in the UK. Leadership in Health Services, 29 (2). pp. 201-216. ISSN 1751-1879

It is advisable to refer to the publisher's version if you intend to cite from the work. http://dx.doi.org/10.1108/LHS-02-2016-0009

For more information about UCLan's research in this area go to http://www.uclan.ac.uk/researchgroups/ and search for < name of research Group>.

For information about Research generally at UCLan please go to http://www.uclan.ac.uk/research/

All outputs in CLoK are protected by Intellectual Property Rights law, including Copyright law. Copyright, IPR and Moral Rights for the works on this site are retained by the individual authors and/or other copyright owners. Terms and conditions for use of this material are defined in the policies page.

\section{CLoK}

Central Lancashire online Knowledge www.clok.uclan.ac.uk 


\section{Exploring leadership in the context of Dentistry in the UK}

Despite considerable research there is still no agreement about leadership theory and practice and it remains an elusive concept, (Barr and Dowding, 2012, p6). Indeed, there is no: "consensus as to its basic meaning, let alone whether it can be taught", (Grint, 2005, p14). This makes it problematic in terms of how and when to develop leadership in specific contexts such as healthcare.

However, leadership remains popular with policy makers in healthcare - particularly clinical leadership. One of the main reasons is a perceived link between the latter and attempts to improve the quality of care, and a consequent need for policy makers to ensure that clinicians are involved in leadership, (Darzi, 2008). This link has been emphasised recently by various reviews and reports such as Keogh Review, 2013, Berwick report, 2013, and the Public Inquiry into the Mid Staffordshire NHS foundation Trust (Francis, 2013). Less attention has been given to leadership in dentistry, compared to the other clinical professions. In fact, it has been argued that little has been done to develop an evidence base for clinical leadership and its impact in dentistry, (Walsh, et al, 2015, p186).

This paper aims to explore some well- known approaches to leadership and the extent to which they are relevant and appropriate to dentists working in the UK dental sector. First, the policy context is outlined; then a range of different approaches to leadership is explored and applied to this context, with emphasis on those approaches considered of interest to dentistry.(although this is necessarily selective given the wide range of approaches available); and finally, the implications are discussed.

\section{Policy context}

The policy context consists of the NHS, and private, and corporate dental sectors. Overall, this context has gone from a period of relative stability to one of considerable change, (Willcocks, 2015). There are now many challenges facing dentistry including:

"ever escalating NHS regulations, possibly reduced NHS dental funding, regulators ( [Care Quality Commission ]CQC and [General Dental Council] GDC), multiple inspections of practices, tiering leading to deskilling of non-specialists, corporate practices, increased litigation, high patient expectations, and decreasing disease", ( $\mathrm{O}^{\prime}$ Reilly and Jacobs, 2015, p 2).

In the private sector there are significant changes, including an increase in the corporate dentistry sector and growth of private dental insurance schemes, (Dancer and Taylor, 2007, p13). In the NHS, various reforms have been introduced changing the structure and operating processes, such as the planning and commissioning of dental care. The expectation is that clinicians will assume a leadership role and get involved at various levels. Thus, dentists might be expected to influence the commissioning of primary care dental services, promote quality in dentistry, and become involved in clinical leadership roles, 
(Walsh, et al, 2015, p186). Similarly, they will be expected to foster localism and promote clinician- led services, (Brocklehurst, et al, 2013, p243).

\section{With regard to the structure, NHS England is able to exert considerable influence on} dentistry, given its responsibility for commissioning all dental services, administering NHS dental contracts, ensuring value for money, facilitating innovation, delivering return on investment and supporting optimum delivery of services, (National Commissioning Board (NCB),2013). Also important, local professional networks (LPNs) have been introduced to provide clinical advice to commissioners about dentistry, and provide local clinical leadership. These are seen as an important development in that dentists are expected to become members of the boards of LPNs, helping to "lead change and drive up the quality of service provision", (NCB), 2013, cited in Walsh, et al, 2015, p186).

As noted earlier, the structure of the dental industry itself is changing, with the growth of large scale corporate dental practices. However, most dentists still work in relatively small practices and may be owners and partners in such businesses. The latter may be NHS, private or mixed practices. They may also work in NHS dental services in specialist centres, dental hospitals, or in secondary care ie hospital dental services. Traditionally, dentists have worked as independent practitioners- albeit they may have NHS contracts- and they have had considerable autonomy. In fact, dentists as independent practitioners:

"have strongly determined their own practice culture and directed all aspects of their practice in a virtually autonomous state", (Dancer and Taylor, 2007, p15).

In addition, various factors are driving an impetus towards changing the skill mix in dentistry, with greater use envisaged for dental therapists to supplement the work of dentists, (Bullock, and Firmstone, 2011, p191). Hitherto, dentists carried out most of the treatment in the surgery, (Dancer and Taylor, 2007, p16).This has the potential to affect the dentists' professional autonomy, identity, and status: like doctors, dentists' identity is centred on their autonomy, (Andersson, 2015, p91). The latter is a defining characteristic of being a professional, along with specialist knowledge, ethical conduct, social recognition, and value,(Cribb and Gewirtz, 2015, p26). It is possible that one strategy dentists may use in this situation is: " to protect their clinical roles and maintain traditional boundaries", (Brocklehurst and Tickle, 2011, p267).

Also, a new dental contract, currently being piloted, may bring about further change in dentistry which will have an impact on the role of the dentist. New systems of remuneration are being tested alongside the contract, (Willcocks, 2015). ). These changes to the dental contract have to be seen in the wider context:

"[it] will become even more complex with contract reform, an ageing population, increased financial scrutiny and budget caps... we [dentists] will be forced to work innovatively and 
engage with patients, collaborate with fellow healthcare sectors and commerce in ways never seen before", ( Ford, 2014, p223).

Dentistry, therefore, like other healthcare professions, is going through a period of major change in a context of reduced public funding, and increased Government emphasis on quality of care and accountability. Changes to the nature of the profession and its relationship to related professions are underway, and also changes to funding, dental contracts and commissioning which will have considerable impact on the profession. This context makes it imperative that the profession is able to respond to these challenges. It is part of the rationale for dentists taking a more proactive leadership role, alongside the fact that leadership is of growing importance more generally for the clinical professions given its impact on quality.

The next section builds on an earlier paper about leadership in dentistry, (Willcocks, 2011). It aims to explore individual leadership approaches in the context of their interest and relevance to dentists in the UK context; they will also be contrasted with a collective approach to leadership. The rationale for choosing these various approaches is that each of them offers a particular insight into the leadership role of dentists, from differing and potentially contrasting perspectives. They enable a focus on a range of personal qualities, behaviours, and attributes relevant to the leadership role of dentists, and relate these to the changing context of dentistry, and take account of the dynamics of change. They also go beyond individual leadership and take into account a more collective approach in keeping with developments in clinical leadership.

\section{Approaches to leadership}

Traditional approaches to conceptualising leadership focus on individual leaders and have been described as 'leader-centric', (Hartley and Benington, 2010, p 17). Such approaches focus on, for example, personality traits, differing skill or competency sets, emotional intelligence, leadership styles/ behaviour, or the importance of situation/ context, the relationship with change, or the interface with the wider system. These assume leadership is an individualistic as opposed to shared activity, premised on the qualities or attributes of the individual leader.

Traits or personality approach

The traits or personality approach has a very long ancestry but it is still considered relevant in the healthcare context. Indeed, the idea of the 'strong' leader and the leaders' personality traits remains popular in healthcare, (Hartley and Benington, 2010, p17). It is pointed out that job descriptions in the health service are still based on trait assumptions, (Barr and Dowding, 2012, p50). Moreover, the various competency frameworks devised by the NHS in recent years have usually incorporated 'personal qualities' such as drive, integrity, and self -belief, as part of the framework. In fact, it has been argued that personal 
qualities represent the main foundation of such frameworks, (NHS Leadership Academy, 2013).

The idea is that effective leaders have certain personal qualities that equate with being a successful leader. Therefore, trait theory has attempted to identify a list of such traits, although there is a debate about whether these traits are innate or capable of being acquired or developed through training. Various attempts have been made to identify a set of optimal or common personality traits associated with leadership. West et al, for example, in a report on leadership in healthcare note that core personality traits associated with leadership effectiveness, might include high energy level, stress tolerance, self- confidence, emotional maturity, integrity and so forth, (West et al 2015, p7). Similarly, Yukl states that, in addition to these, internal control orientation, extroversion, and conscientiousness are important to leadership effectiveness, (Yukl, 2013, p166). Recent research has linked leadership to intelligence, (IQ), (Barr and Dowding, 2012, p50). Gill notes that superior IQ has been singled out by some observers as being important to successful leadership, although this may be a disadvantage if it leads to incompatibility with followers or 'over intellectualising' the decision making process, (Gill, 2011, p64).

Some of these traits associated with leadership are relevant to dentists in both their clinical work and their clinical leadership role, for example, stress tolerance, self- confidence, or IQ. Charisma has been identified as important by dentists themselves, ((Walsh, et al 2015, p196). The latter may be a significant trait in so far as it enables dentists in their leadership role to influence followers and bring about commitment to change, (Avery, 2004, p93). However, it is a disputed concept, (Gopee and Galloway, 2009, p56).

One may debate whether dentists have the necessary traits as part of their clinical training or whether they need to acquire certain traits associated specifically with leadership. The problem is that there remains a lack of agreement about the precise set of traits required by effective leaders. As stated by Grint: "no consensus exists as to which traits or characteristics or competencies are essential or optional", and it is questionable whether leaders actually exist who possess all the traits that have been identified in various lists, (Grint, 2005, p34).

Skills based approach

Alternatively, a skills based approach to leadership may be relevant in the dental context, although there is said to be merit in exploring both traits and skills underpinning successful leadership, (Yukl, 2013, p166)). One definition of clinical leadership in dentistry is that it is:

"the skills required to provide effective patient care", (Moore, et al, 2015, p255).

Similarly, "to lead a practice, dentists [need to be] highly skilled clinicians, respected and trusted by their clinical team", (Sbaraini, 2012, p7). 
These definitions suggest that dentists are 'expert leaders' with high level knowledge and skills underpinning their credibility as leaders, (Gosling, et al, 2012, p81). It has been noted that a major source of influence for clinical leaders is individual clinical expertise, (Hartley and Benington, 2010, p30).

Early research into leadership in this area led to the development of a three part skills model based on the work of Katz, consisting of technical, human, and conceptual skills, with each skill linked to levels in the organisation, (cited in Peterson and Fleet, 2004 , p1298). Later skills models, such as that of Mumford are more complex and suggest problem solving, and social judgement skills, and knowledge are important, (cited in Northouse, 2004, p40). Technical skill is valued at lower levels in the organisation. In dentistry, relatively small and flat practices suggest this skill is important. Like surgeons generally, dentists value technically ability as the most important individual skill, but this has begun to change with recognition of the importance of teamwork in improving quality, (Suliman et al, 2013 p 6). As noted by Chambers:

"we would like the surgeon to be technically proficient but if he or she is not capable of successfully leading a team, the patient will also suffer", (Chambers, in Walshe and Smith, 2011).

Team leadership, therefore is not just about technical ability; human skills are also required. This is supported by dentists in a recent research study, (Walsh, et al 2015).

The skills or competency based approach is popular in healthcare, as evidenced, for example, in the competency approach, devised for doctors and other staff, (Clark and Armit, 2000). In fact, there have been several versions of such frameworks beginning with the Leadership Qualities Framework, (2006), then a Medical Leadership Competency Framework (2010), Clinical Leadership Framework, (2011), Leadership Framework (2011) up to the latest version, the Healthcare Leadership model (2014), (Willcocks, 2015, p348). These frameworks are premised on the idea that it is possible to identify and develop core competencies, behaviours, and personal qualities required by leaders. They have attempted to do this generically for a variety of healthcare staff, as in the most recent Healthcare Leadership model, and also specifically, for clinical staff, and for medical staff as in the Medical Leadership Competency Framework in the case of the latter. The competency frameworks purport to identify common developmental skills/ competencies and underpinning knowledge required to be an effective clinical leader, and in the case of doctors, within a specific medical context. These are being used as a basis for leadership training for clinicians at different stages of their careers. However, there is no corresponding competency framework designed specifically for dentists.

Like personality theory, there are problems with this approach because the evidence does not necessarily demonstrate that competency frameworks work ie enable leaders to be effective, (West, et al, 2015, p19). 
Emotional intelligence

There is also some interest in emotional intelligence, (EQ), as an underlying part of leadership, (Skinner and Spurgeon, 2005, p2). Indeed, various components of EQ were identified as important under the umbrella of 'personal qualities' in the leadership frameworks identified above, such as the Leadership Qualities framework, or the Medical Leadership Competency Framework,( Nichol, 2012, p61). EQ has been identified as a core competence for healthcare leaders and may be a factor in developing leaders' effectiveness, for example, determining the leaders' ability to develop effective working relationships, or facilitating organisational change. Leaders may call upon their EQ when enacting their leadership role, which may be defined as:

"the ability to understand oneself and others, to manage one's emotions, and to use interpersonal skills to respond to other people in appropriate ways", (Gill, 2011, p304).

EQ can be broken down into five components: self -awareness, self- regulation, motivation, empathy and social skill, (Goleman, 2004, p3). To some extent, these generic components underpin other approaches to leadership. They represent a checklist of competencies for dentists concerned with developing the emotional side of their leadership role. For example, dentists might focus on developing self-awareness, such as awareness of their' own emotions vis a vis their colleagues; they may need to develop empathy and social skills to understand and relate effectively to their colleagues, and they may need to improve their ability to build and sustain effective relationships within their practice. Such competencies are said to be important in terms of ensuring that leadership in healthcare is not just task, but relationship- based, (Skinner and Spurgeon, 2005). Indeed, it has been said that:

"after many years acknowledging the importance of task and more cognitive-oriented conceptions of health leadership, the balance appears now to be switching towards an understanding of the importance of the emotional and relationship dimension", (Skinner and Spurgeon, 2005, p11).

This change in emphasis towards emotional aspects is relevant to dentistry as the context can be said to be inherently emotive. There are 'unique stressors', in care environments like dentistry, the consequence of the fact that work involves people, not objects, and in many cases dealing with vulnerable people, (Broomfield, Humphris and Kaney, 1996, p5).

In practice, there may be a choice for leaders, between either the emotive or cognitive dimensions of leadership, that is between EQ, or, alternatively, expert knowledge and IQ, (Gosling, et al, 2012, pxv). However, both may be important.

Styles or behaviour

Approaches based on styles or behaviour, - what effective leaders actually do - may also be of interest in terms of focusing on the actual behaviour of leaders, as opposed to 'who they 
are', as in the traits approach, (Hartley and Benington, 2019, p77). They offer debate about the merits of different leadership styles, for example, autocratic or democratic styles of leadership. A range or continuum of styles is possible, although researchers have identified essentially two sets of leadership styles/behaviours- task behaviours and relationship behaviours- the former is concerned with achieving goals; and the latter with establishing good working relationships, (Northouse, 2004, p65). In dentistry, historically, the dentist has been used to adopting a directive or task based style, thus, they are:

"accustomed to being the decision maker and taking a proactive role in both the business and clinical elements of their work", (Dancer and Taylor, 2007, p15).

However, it is possible that there is a shift from historical emphasis on autocratic leadership styles by practice owners towards a more democratic team based style of leadership. Barr and Dowding cite a wider range of styles that might have more resonance with this change in dentistry ie coercive, authoritative, affiliative, democratic, pacesetting, and coaching styles of leadership, (National Professional Qualification for Headship, 2005, cited in Barr and Dowding, 2012, p17). Similarly, Bass et al, report on a wider range of leadership styles ie directive, consultative, participative, negotiative, and delegative, (Bass et al cited in Gill, 2011, p 73).In the changing climate in dentistry a coaching or delegative style may be more appropriate for dentists who wish to encourage team development. This also relates to earlier discussion about EQ in that leaders with high EQ may be more likely to adopt a coaching style of leadership, (Gosling, et al, 2012, p77).

A specific approach-'servant leadership' -suggests adopting an altruistic style or set of behaviours towards followers, ie leaders are there to 'serve' and support their colleagues. This has also attracted interest in healthcare settings, (Gopee and Galloway, 2009, p57). Servant leadership may resonate with the ethical principles of dentistry, and the obligations in professional practice such as developing trust, collegiality, and empowering fellow professionals, (Barr and Dowding, 2012, p64). What is important is the relationship between individual leader and followers with the attributes of the individual leader- such as empathy, integrity and competence - being used to facilitate the empowerment of followers to achieve shared goals or vision, ( Washington, et al, 2006, p701). In this context, it has been argued that followers are equally important as leaders, (Grint and Holt, 2011, p8). Followers may have complex motivational patterns, and thus: "the essence of leadership is the ability to use identified motivational patterns to influence others", (Kets De Vries, 2004, p188).

Like other theories, style/behaviour theories have problems, in that researchers have not been able to identify an optimal leadership style of universal relevance in all situations, (Northouse, 2004, p75). They might offer insight into the impact of leadership behaviours on practice but more attention is needed to the specific context.

Situational or contingency leadership 
Building on the above, there are approaches that focus more specifically, on the relationship between the individual leaders' style and behaviour and different aspects of the context, as in situational or contingency leadership. Thus, the dental context will be an important factor in determining the appropriateness of particular leadership approaches.

In dentistry, different contexts - for example, whether the practice is in the NHS, private, mixed, or corporate sector - might influence the extent to which specific leadership styles are able to influence change or motivate followers. These contexts present potentially very different challenges for leadership in that they each have different employment patterns, management arrangements, contracts, goals, expectations, and regulations, and differ in terms of size of practice, culture and history. In the NHS there are external constraints in the form of higher level policy requirements and the involvement of outside organisations such as regulators and commissioners, for example, GDC, CQC or NHS England . Funding may be a considerable constraint. In the corporate sector there are different organisational requirements and more emphasis on ownership, corporate growth and profit. Funding may also be a constraint from the view of corporate ownership.

These contexts will present with differing staffing arrangements which, in leadership terms, means differences between followers, such as maturity of followers, the quality of relationships between followers and leader, nature of tasks, culture and power within teams and so forth, (Gill, 2011, p79). It is said that a key factor in the above is the 'maturity' of followers in relation to the nature of the task, (Gosling et al 2012, pxxiv). In relatively new dental practices such as those developing in the corporate sector there may be constraints with regard to the time lag in developing the maturity of staff. Thus, for example, one may argue that the choice of leadership style should be a directive style for relatively new organisations and a supportive style for more established mature organisations.

Choice of leadership style in these different contexts might depend on how far staff will accept change, tolerate uncertainty or accept responsibility, depending on the nature of the dental practice. This is something that dentists as leaders may have to make a judgement about in their practice, for example, how directive they need to be.. In the words of situational leadership, this relates to the 'readiness' of staff to carry out a task, the extent of their ability and confidence, (Gill, 2011, p80). In dentistry, this may depend on how dynamic the practice is in relation to taking up opportunities presented by new contracting arrangements and changes to government policy. Equally, it may depend on resources available, time constraints and size of the practice. This may also be related to the culture of dentistry, as discussed earlier, for example, whether it is autocratic or team -based, or something else, (Moore, et al, 2015, p258).

Leadership and organisational change

Another approach conceptualises leadership in terms of its role in relation to leading organisational change. It could be argued that this relationship is axiomatic in the current 
healthcare context. Leadership, as opposed to management, has traditionally been associated with vision, goals and organisational change. This is one of the espoused aims of one of the more well- known approaches, transformational leadership, (Gopee and Galloway, 2009, p57). However, providing vision, or goals, may be problematic particularly in the healthcare context, for example, this may not be a purely rational decision making process. This has led some observers to suggest that leaders have a role as 'sense maker', that is, to make sense of an uncertain environment, (Hartley and Benington, 2010, p53).

A specific approach associated with change-transformational leadership- focuses on both the individual skills and behaviour of the leader and the impact on 'followers', and is associated with the behavioural approach discussed earlier, (Hartley and Benington, 2010, p86). It also utilises both conceptual and emotional competence so there is a link with earlier discussion about EQ, (Skinner and Spurgeon, 2005, p2). 'Followers' may need to be motivated to accept common goals such as those associated with quality. In order to do this, the model derived from the work of Bass suggests leaders are required to adopt and adapt their behaviour guided by four factors, that is, charisma or idealized influence; inspirational motivation; intellectual stimulation and idealised consideration, (cited in Northouse, 2004, p175). It was noted earlier that a study of dentists themselves identified the first factor, charisma, as important in dentistry, although charisma is said to be hard to define and measure, (Gosling, et al, 2012, pxix). With regard to the other factors, motivation and intellectual stimulation may help promote engagement with dental professionals and stimulate change in clinical practice. In fact, there is empirical support for the importance of transformational leadership in bringing about change in dental practice, (Sbaraini, 2012, p12).

The link with organisational change is apparent when one looks at the outcomes of investigations into well- known organisational failures in the NHS. The latter: "have repeatedly emphasised the importance of leadership in securing and improving quality and safety", (McKee, et al, 2015, p11). It has been noted, however, that this is a potential issue in the case of dentistry:

"to date, there has been little evidence of clinical leadership by general dental practitioners (GDPs) in service design and quality improvement projects", (Moore, et al, 2015, p255).

Leadership may need to be developed to respond to changes in the policy context, such as new technology, or changes in government policy.

Leadership and networks

Another approach focuses on leadership in terms of the leadership role in network organisations. The latter are increasingly used in healthcare settings, for example, there is considerable use of managed clinical networks. Thus, leadership may occupy roles at the interface between the dental practice, organisation and wider community, such as 
commissioning organisations, advisory bodies, or NHS England. It has been argued that leadership is likely to transcend organisational barriers and the leadership role is about connecting with different parts of the system or network, (Gopee and Galloway, 2009). In this view, leadership is a cross boundary role or function and may be described as 'connective leadership', (Willcocks, 2010, Gopee and Galloway, 2009). The challenge here is to enable dentists to go beyond their 'practice bubble', that is to step outside the confines of their practice (Walsh, et al, 2015, p 196).

Dental practices may have more than one site or location, or the practice may be a corporate practice with multiple practices. Equally, dentists are part of the wider system involving statutory bodies such as NHS England, (or its local area teams), and LPNs. Effectively, networks involve inter-agency working involving potentially very different organisations with different values, culture, and missions. This is likely to call for different approaches to leadership. It is argued that there are challenges for leadership in networked organisations, such as dealing with the possibility of internal rivalry, inability to adapt or to stay with the network, (uncoupling) and so forth, (Hartley and Benington, 2010, p64).There is a 'connective' leadership role in terms of holding the network together, ensuring an element of unity in an essentially pluralistic arrangement.

Networking is likely to be a new way of working for dentists who historically have operated as independent autonomous practitioners in their own small business. It brings with it different conceptions of power and authority. Leadership is unlikely to be based on traditional conceptualisations of power involving hierarchical mechanisms. Instead, dentists who become involved in networks are more likely to need informal power and influence over colleagues who are not part of their own organisation. Therefore, it calls upon some of the skills and personal qualities highlighted in earlier approaches to leadership such as EQ, team working skills, influencing and communication skills and change leadership skills.

The approaches described above rely ultimately on the cognitions, actions and behaviour of individual leaders. This is a traditional view of leadership which has a considerable range of theoretical and empirical research underpinning this approach. However, it can be noted that individualistic leadership is the subject of criticism. For example, it has been suggested that individual leaders may have mixed motives behind their actions, they may have individual as opposed to organisational goals, and may be manipulative in achieving these goals, and may see followers as:

"simply cogs in the organisation to be moved around and /or dismissed as deemed necessary", (Gosling et al 2012, p120).

Collaborative / shared leadership

The alternative is to conceptualise leadership in more collaborative terms. There has been growing interest in the possibilities presented by collaborative or shared approach to 
leadership, the idea that leadership is a shared, collective or distributed endeavour. This may be a relevant given the potential shift towards dentists working in larger teams in the future, (Walsh, et al, 2015 p197). This may be contrasted with the idea of the 'heroic' individual leader, where the emphasis is on individual qualities and attributes or leadership roles or function, or leadership at the top of the organisation.

Contrary to this, shared leadership is seen as group -level concept in which leadership is characterised as distributed throughout the organisation, enacted by more than one individual, based on the central importance of social interactions, and leading to organisational learning, (Avery, in Pearce and Conger, 2003, p22). Adopting a shared leadership approach in dentistry means taking more account of social relationships, and group dynamics, as opposed to the traditional emphasis on individual actions and behaviour. Equally, there is more emphasis on achieving organisational learning.

Thus, a shared leadership approach goes beyond the individual dimension, and a focus on individual leaders, and highlights concepts such as inclusiveness, collectivity, and collaboration, ( Oborn, et al,, 2013, p254). While there may still be a role for individuals, "[it] recognises the inclusive and collaborative nature of the leadership process" and there is an argument that this approach is particularly relevant to professionals [like dentists] in the knowledge sector, (Oborn, et al, 2013, p253).

With regard to its collective nature, the point is also made that shared leadership is context- specific. It has been suggested that:

" shared leadership is portrayed as a dynamic, multi directional, collective activity that like all human action and cognitive sense making is embedded in the context in which it occurs", (Avery in in Pearce and Conger, 2003, p23).

This approach may also be of interest in the healthcare context, indeed, it is emphasised in the Medical Leadership Competency Framework. In dentistry, it is thought that the new dental contract being piloted will bring about 'greater use of the whole dental team', (Walsh, et al, 2015, p186). Leadership may be a collaborative process enacted by various members of the dental team, depending on specific circumstances or the nature of the task, although, as previously stated, this may conflict with the idea of the dentist as the main decision maker and owner in a practice, (Dancer and Taylor, 2007). Unlike formal leadership models, shared leadership may be informal or emergent and may be "dissociated from the organisational hierarchy", that is, not related necessarily to position power, (Gosling, et al 2012, pxxx). It may be appropriate for a clinical setting in that it is a "new way of sharing power", a way which ensures:

"the distribution and allocation of leadership power to wherever expertise, capability and motivation sit within organisations", (West, et al, 2014, p7). 
As discussed earlier, however, in the dentistry context there may be some reluctance to change the balance of power to include greater devolution to other members of the dental team, even though this may bring greater opportunities for cross disciplinary learning, and greater responsiveness and adaptability to change.

While there is much to support it, a criticism of shared leadership is that it could lead to confusion about who was in charge, and that hierarchical or individualistic leadership might still be needed, (McKee et al, 2015, p11). In a shift to a shared approach, this confusion might manifest itself in dentistry where there is a history of hierarchical control and central direction.

\section{Implications and Recommendations}

Given the various influencing factors mentioned earlier, such as policy and structural changes, culture, and the importance of quality, it is clear that there is a role for clinical leadership in dentistry. Dentists are currently somewhat behind other clinical professionals such as doctors and nurses in accepting and engaging with clinical leadership. However, the Faculty of General Dental Practitioners, ( FGDP,UK), point out that dentists can "no longer rely on chance for developing effective managers and leaders", (cited in British Dental Journal, 2008, p498).

One implication, therefore, is fostering the involvement of dentists in this way. Clinical engagement has been problematic in the case of doctors in recent years, and may be the case with dentists. Another implication is ensuring that dentists are able to assume such roles by virtue of experience, training and career development. Walsh, et al argue that both education and naturalistic learning are important in facilitating this, (Walsh, et al, 2015, p196).However, this will partly depend on the approach to leadership taken, for example, in the case of individual leadership approaches, attention would be focused upon training and development in appropriate skills, and behaviour, or identifying appropriate personality traits associated with effective leadership. It would be necessary to identify particular skill sets or competency models that might be particularly relevant to clinical leadership in dentistry. Such skills or models would have to take account of the context/situation in dentistry and the way in which it has developed historically. With regard to developing EQ, it has been argued that individualised training or coaching could be provided, giving more attention to the brains limbic system, (feelings, emotions, and so forth). One of the challenges with this approach, it is suggested, is to "break old behavioural habits and establish new ones", (Goleman, 1998, p4).

Alongside this, there could be more focus on cultivating personal values and developing the culture underpinning effective leadership, as in approaches associated with servant leadership approach. Walsh, et al report that: 'a strong culture of leadership development in dentistry [is] paramount". (Walsh, et al, 2015, p196). 
Some aspects of leadership may be present or nurtured as part of clinical training, such as in undergraduate and postgraduate dental training. For example, EQ, maturity, self confidence, and integrity, are core attributes of the dentists' clinical practice. However, there may a developmental transition needed in adopting and adapting attributes and behaviours associated with clinical practice into the leadership role. It is said to be difficult for someone moving from a technical role to a managerial or leadership role, (Peterson and Fleet, 2004 p 1297). It is not always obvious that some clinical skills, qualities and behaviour can be successfully transposed into the leadership role such as communication skills, empathy, problem solving, or insight into human behaviour. More attention should be given to leadership, alongside clinical practice, in undergraduate dental training, (Walsh, et al, 2015, p197).

With regard to the transformational leadership approach, a key emphasis would be on developing appropriate influencing skills and behaviours so that these may enhance interpersonal relationships, team working and bring about commitment to transformational change, (Gopee and Galloway, 2009, p58). Transformational leadership models have been popular in healthcare and may translate to the dentistry context, particularly given the extent of change currently going in in this context. However, one issue may be that medical leaders, historically, have tended to adopt transactional or managerialist approaches, because of the structure and culture of healthcare, when transformational leadership may be more effective, (Chapman, 2014, p285).

If one takes a network approach to leadership, taking account of the wider healthcare system, and where it is important for leaders to make connections outside the practice, then the focus is on developing networking and influencing skills and behaviours. There will be less emphasis on formal authority given that various organisations will be involved outside of the area of authority of the individual dentist.

With regard to a shared leadership approach, development would be geared to a wider range of staff within dental practice, given that the leadership role might be shared. The emphasis would be on developing collaborative working, fostering the right values underpinning this approach, ensuring that the culture is supportive of a shared approach to leadership. This is a less tangible way to develop staff and may encounter resistance. It has been suggested that, unlike GPs, dentists have had less experience of working in a cross functional way, utilising shared decision making and teamwork, (Dancer and Taylor, 2007, p15).

In terms of overall recommendations, the main one is to ensure that clinical leadership is accepted and acknowledged in dental practice as a necessary way forward if dentistry is to meet the challenges presented in the current and future policy context. As noted, this has been problematic with other professions so it is important to identify the extent of support for or against leadership in dentistry and to foster clinical engagement. 
With regard to a particular approach, each of the approaches reviewed here are, to some extent, incomplete on their own but together offer a rounded view, thus ensuring that important aspects of leadership are taken into account when applied to the dental context. While shared leadership is important and a recent policy initiative, nevertheless, leadership may still be exercised at the individual level. The individual level is still a focus in healthcare, as evidenced by various leadership competency schemes. Moreover, dentists are required to exercise an individual clinical leadership role regardless of their involvement in formal management arrangements.

Therefore, individual approaches such as the traits approach, competency approach and those associated with individual leadership behaviour remain valid. However, it is important that identification and development of individual traits, competencies or behaviour is not seen as a generic solution, that is, it has to be related to the nature of the dental context. This approach has already been taken with the development of a competency framework for the medical profession, ie the medical leadership competency framework.

So a competency framework for the dental profession, based on the dental context, may be one way forward, providing it remains a flexible and adaptable as opposed to overly prescriptive. With regard to the latter, it is important that any leadership solution is responsive to the changing context:

"leaders must be able to adapt to different system changes and different kinds of challenges that are encountered. Shifting the leadership approach according to the external or internal context during a change process may be important", (DaCosta, 2012, p577).

It also needs to be able to accommodate both individual and shared approaches to leadership. Such a framework could be informed by considering how best to equip dentists with the right skills, competencies, and behaviours, to enable them to assume a leadership role, both at the individual role and collectively as part of shared leadership. To succeed, the framework needs to be accepted and owned by the profession and implemented across undergraduate, postgraduate and continuing practice levels as in the Medical Leadership Competency Framework. It is imperative that leadership, especially clinical leadership, is seen as part of the continuing role of all dentists not just those in management or formal leadership roles.

\section{Conclusion}

While all these approaches to leadership may be related to effectiveness, one may note that such a relationship has been questioned by critical leadership scholars, (Hartley and Benington, 2011, p12). Indeed, one may debate the subjective nature of effectiveness itself. However, it is clear that leadership is a topic worthy of debate by dentists and the wider policy community. This is particularly so given the changes outlined above in the policy 
context. Leadership will become increasingly core to the practice of dentistry as it has become for the other clinical professions, particularly doctors.

While there is no one right way to pursue leadership in dentistry - and most approaches to leadership have their strengths and weaknesses- it is argued that the debate will benefit from adopting an eclectic stance to the multitude of theories and concepts available. This paper has suggested that there may be merit in exploring specific theories associated with individual or shared leadership approaches, although there are many more available.

Each of these offers insight into a particular aspect of leadership. For example, individual approaches offer insight into personal qualities, skills and behaviour, and how this interacts with the context. Shared leadership offers insight into the informal, group, and collaborative dimension of leadership. What is important is being able to draw out the implications of each of these, ensuring that the specific context of dentistry is acknowledged. One way forward might be to use these various approaches to leadership to inform the development of a dental -specific model of leadership.

\section{References}

Andersson, T. (2015), The medical leadership challenge in healthcare is an identity challenge, Leadership in Health Services, Vol28, 2 pp83-99

Avery, G C (2004) Understanding leadership, Sage, London

Barr, J and Dowding, L, (2012) Leadership in healthcare, Sage, London

Berwick, D, (2013), A promise to learn, a commitment to act: improving the safety of patients in England, DOH London

British Dental Journal, (2008), news item- Don't leave leadership to chance, warns FGDP (UK), British Dental Journal, 14 June 204, p498

Brocklehurst, P. Ferguson, J, Taylor, N and Tickle, M (, 2013), What is clinical leadership and why might it be important in dentistry?, British Dental Journal, 214. Pp243-246

Brocklehurst, P and Tickle, M ( 2011), The policy context for skill mix in the NHS in the UK, British Dental Journal, 211, pp265-269

Broomfield, D Humphris, G and Kaney, S( 1996), Stress in junior hospital medical and dental staff: a descriptive account of their concerns and needs, Health Manpower Management, 22, 3 pp 5-9

Bullock, A and Firmstone, V (2011), a professional challenge: the development of skill mix in UK primary care dentistry, Health Services Management Research 24 pp 190-195 
Chambers, N Leadership and governance, in Walsh, K, and Smith, J eds (2011) Healthcare Management, OUP, Berkshire

Chapman, A L N, Johnson, D, and Kilner, K (2014) Leadership styles used by senior medical leaders, Leadership in Health Services, Vol 27, 4, pp 283-298

Clark, J and Armit, K (2000), Leadership competency for doctors: a framework, Leadership in Health Services, Vol 23, 2 pp115-129

Cribb, A and Gewirtz, S, (2015) Professionalism, Polity Press, Cambridge

DaCosta, J, (2012) Leadership models for healthcare improvement, British Journal of Healthcare Management, Vol 18, No 11 pp575-580

Dancer J M, and Taylor, C A (2007) Dentistry is different: practitioner perceptions of the business of dentistry, Clinician in Management 15, pp 11-27

Darzi, A (2008) High quality care for all: NHS next stage review final report, London, DOH

Ford, J ( 2014) Engaging dental professionals in NHS leadership-the challenges, the opportunities and the risks, British Dental Journal, 217, pp221-222

Francis, R, QC, (2013), Report of the Mid Staffordshire NHS foundation trust public Inquiry, Stationery Office, London

Gill, R, (2011) Theory and practice of leadership, Sage, London

Goleman, D,( 2004), What makes a leader? Harvard Business Review, January, pp1-11

Gopee N, Galloway, J (2009), Leadership and management in healthcare, Sage, London

Gosling, J, Jones, S and Sutherland, I, (2012) Key concepts in leadership, Sage, London

Grint, K (2005) Leadership: Limits and possibilities, Palgrave Macmillan, Basingstoke

Grint, K and Holt, C (2011), Followership in the NHS, Kings Fund, London

Hartley, J and Benington, J (2010), Leadership for Healthcare, Policy Press, Bristol.

Hartley J and Benington, J, (2011) Recent trends in leadership: thinking and action in the public and voluntary sectors, Kings Fund, Commission on Leadership and Management in the NHS London

Kets De Vries, M (2004) Organisations on the couch: a critical perspective on organisational dynamics, European Management Journal, 22, 2, pp 183-200

Keogh, B (2013), Review into the quality of care and treatment provided by 14 hospital trusts in England,: Overview report, DOH, London 
McKee, L Charles, K, Dixon-Woods, M, Willars, J, and Martin, G (2015), New and distributed leadership in quality and safety in healthcare, or old and hierarchical? An interview study with strategic stakeholders, Journal of Health Services Research and Policy, 18, 2, pp11-19

Moore, D Saleem, S Hawthorn, E Pealing R, Ashley, M and Bridgman, C, (2015) Healthy gums do matter: a case study of clinical leadership within primary dental care, British Dental Journal, Vol 219, No6 Sep 25

NCB (2013) Securing excellence in commissioning NHS dental services, February, pp1-35 Nichol, E D (2012), Improving clinical leadership and management in the NHS, Journal of Healthcare Leadership, 4 pp 59-69

NHS Leadership Academy, (2013),Healthcare Leadership model, NHS Leadership Academy, Leeds

Northouse, P G, (2004) Leadership: theory and practice, Sage, London

Oborn, E,Barrett, M, Dawson, S (2013) Distributed leadership in policy formulation: a sociomaterial perspective, Organisation Studies, Vol 34, 2 pp 253-278

O'Reilly, M P, and Jacobs, A V, (2015), Mental health: would you choose a dental degree? British Dental Journal, 21910 July $\mathrm{p} 2$

Pearce, C L and Conger, J A eds(2003), Shared leadership-reframing the hows and whys of leadership, Sage, London

Peterson, T O, and Fleet, D Van, (2004) The ongoing legacy of R L Katz, Management Decision, Vol 4210 pp 1297-1308

Sbaraini, A (2012) What factors influence the provision of preventative care by general dental practitioners, British Dental Journal, 212, 8 June, p1-16

Skinner and Spurgeon, (2005), Valuing empathy and emotional intelligence in health leadership: a study of empathy, leadership behaviour and outcome effectiveness, Health Services Management Research, 18, 1-12

Suliman, A, Klaber, R E, and Warren, O J, ( 2013), Exploiting opportunities for leadership development of surgeons within the operating theatre, International Journal of Surgery 11, 1 pp 6-11

Walsh, J, Taylor, N, Hough, D, and Brocklehurst, P, (2015) A qualitative evaluation of a pilot leadership programme for dentists, Leadership in Health Services, Vol 28, 3 pp185-199

Washington, R R, Sutton, CD, and Field, H S, (2006), Individual differences in servant leadership: the roles of values and personality, Leadership and Organisation development Journal, Vol 27, 8 pp700- 716 
West, M, Armit K, Loewenthal, L, Eckert, R West T and Lee, A (2015), leadership and leadership development in healthcare: the evidence base, Faculty of Medical Leadership and Management, Kings Fund, Centre for Creative Leadership, London

West, M, Eckert, R, Steward, K and Pasmore, B, (2014), Developing collective leadership for healthcare, Kings Fund, Center for Creative Leadership, London

Willcocks S G (2010) Leadership; a challenge for GPs, British Journal of Healthcare Management, Vol 16 no 10 pp468-473

Willcocks S G (2011) Leadership theory: implications for developing dental surgeons in primary care, British dental Journal,

Willcocks S G (2015) Exploring the use of strategic frameworks in dental practice, British Dental Journal,

Willcocks, S G and Wibberley, G, (2015) Exploring a shared leadership perspective for NHS doctors, Leadership in Health Services, Vol 28, 4 pp345-355

Yukl, G (2013), Leadership in organisations, Pearson, Harlow Essex. 